\title{
Experimental study on moonpool resonance of offshore floating structure
}

\author{
Seung-Ho Yang ${ }^{1,2}$ and Sun-Hong Kwon ${ }^{1}$ \\ ${ }^{1}$ Department of Naval Architecture and Ocean Engineering, Pusan National University, Busan, Korea \\ ${ }^{2}$ Marine Research Institute, Samsung Heavy Industries Co. Ltd, Geoje, Korea
}

\begin{abstract}
Offshore floating structures have so-called moonpool in the centre area for the purpose of drilling, installation of subsea structures, recovery of Remotely-Operated Vehicle (ROV) and divers. However, this vertical opening has an effect on the operating performance of floating offshore structure in the vicinity of moonpool resonance frequency; piston mode and sloshing mode. Experimental study based on model test was carried out. Moonpool resonance of floating offshore structure on fixed condition and motion free condition were investigated. And, the effect of cofferdam which is representative inner structure inside moonpool was examined. Model test results showed that Molin's theoretical formula can predict moonpool resonance on fixed condition quite accurately. However, motion free condition has higher resonance frequency when it is compared with that of motion fixed. The installation of cofferdam moves resonance frequency to higher region and also generates secondary resonance at lower frequency. Furthermore, it was found that cofferdam was the cause of generating waves in the longitudinal direction when the vessel was in beam sea.
\end{abstract}

KEY WORDS: Moonpool resonance frequency; Piston mode; Sloshing mode; Model test; Cofferdam.

\section{INTRODUCTION}

Although world economy has the uncertainty, world energy consumption is continuously increasing due to the growth of the world economy. According to the increase of energy demands, high oil prices are lasting and the market of floating offshore structure continues to grow.

Offshore floating structures have so-called moonpool in the centre area for the purpose of drilling, installation of subsea structures, recovery of ROV and divers. However, this vertical opening has an effect on the operating performance of the floating offshore structure in the vicinity of moonpool resonance frequency; piston mode and sloshing mode.

In the past, Fukuda (1977) carried out empirical research regarding the behavior of ship-shaped floating offshore structure. He observed the flow inside moonpool using the models with circular and sqare shape moonpool and studied the effect to the vessel motion caused by the violent flow inside moonpool.

Recently, Molin (2001) has derived theoretical formulas for piston mode and sloshing mode resonance frequency of moonpool using velocity potential and boundary condition. And, he applied those formulas to a barge type vessel with the moonpool in the center area.

Maisondieu and Ferrant (2003) obtained moonpool resonance frequency from Fast Fourier Transform (FFT) of time history of free surface elevation inside moonpool and it was compared with predicted resonance frequency from theoretical formula. Veer and Tholen (2008) performed resistance test for moonpool of the drillship with the ratio of various length to breadth and studied the correlation between the shape of moonpool and increase of resistance, witnessed the variation of free surface

Corresponding author: Sun-Hong Kwon

e-mail:shkwon@pusan.ac.kr 
elevation inside moonpool according to the ratio of draft to moonpool breadth.

Meanwhile, Park (2009) carried out the model test in 2D wave flume to find the variation of flow inside moonpool according to the change of breadth of moonpool and the devices for flow reduction and analyzed the model test results. Taylor et al. (2009) investigated viscous effect on the prediction of violent flow inside moonpool from the idea for the difference between potential based prediction results of free surface elevation inside moonpool and the measurements from model test.

Choi et al. (2010) performed flow analysis for the different shape of moonpool using in-house Computational Fluid Dynamics (CFD) code to investigate complex mechanism of violent flow inside moonpool. Through this study, the overturn of free surface due to the cofferdam and forming process of complex flow field were examined regarding the model with cofferdam.

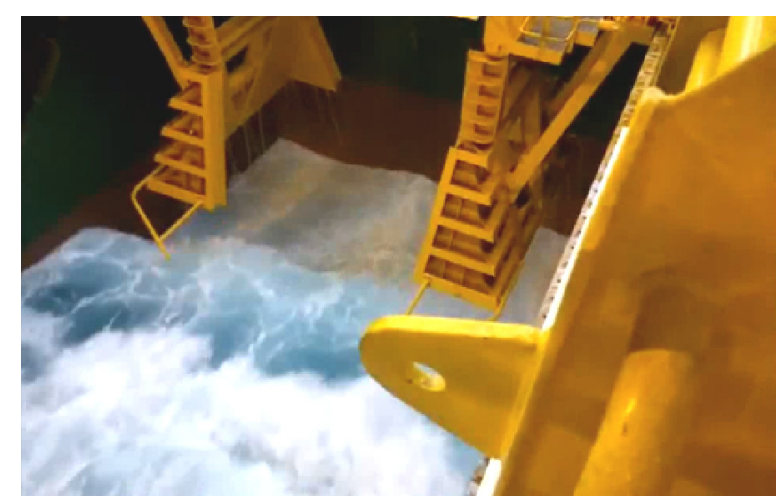

Fig. 1 Violent flow in moonpool.

However, previous studies could not address hydrodynamic characteristics of moonpool such as resonance frequency on motion free condition and the shift of moonpool resonance by cofferdam inside moonpool. According to Yang et al. (2012), moonpool resonance can be predicted through motion analysis of floating offshore structure. For example, surge and heave Response Amplitude Operators (RAOs) present peaks at resonance frequency. At this resonance frequency, added mass and damping show nearly singular pattern. He insisted that moonpool resonance is shifted to different frequency region when the vessel has inner structure like cofferdam inside moonpool.

In this study, the followings were investigated based on model test.

(1) Piston mode resonance frequency in fixed condition.

(2) Piston mode resonance frequency in motion free condition.

(3) Shift of moonpool resonance due to cofferdam inside moonpool.

\section{EXPERIMENTAL SETUP}

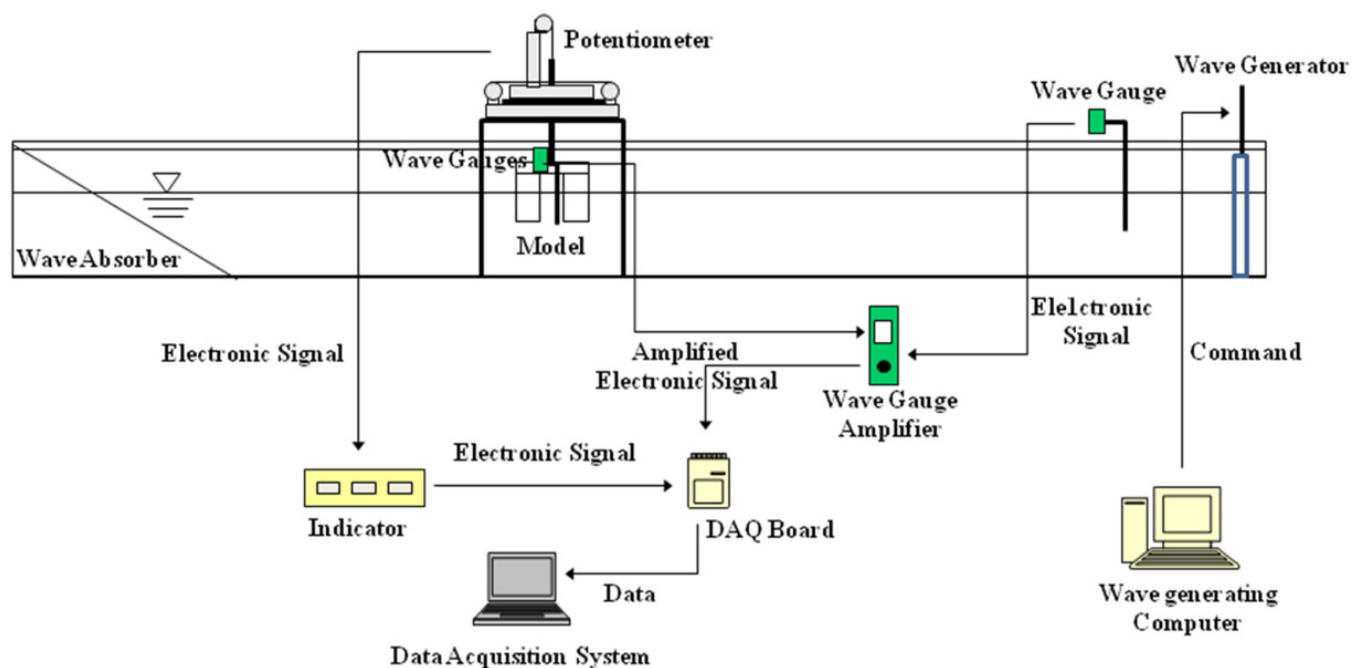

Fig. 2 Schematic diagram for model test. 
Schematic diagram for model test is shown in Fig. 2. Particular dimensions of 2D wave flume and wave maker are shown in Table 1. Type of wave gauge is described in Table 2. NI data acquisition equipment was used for data acquisition.

Table 1 Experimental facility.

\begin{tabular}{|c|c|c|c|}
\hline \multicolumn{2}{|c|}{ 2D Wave flume } & \multicolumn{2}{c|}{ Wave maker } \\
\hline Length & $31.2 \mathrm{~m}$ & Type & Piston \\
\hline Breadth & $0.6 \mathrm{~m}$ & Stroke & Max. $60 \mathrm{~mm}$ \\
\hline Depth & $0.9 \mathrm{~m}$ & Frequency range & Max. $2.0 \mathrm{~Hz}$ \\
\hline
\end{tabular}

Table 2 Specification of wave gauge.

\begin{tabular}{|c|c|}
\hline Type & Sensor wire \\
\hline Wire diameter & $2 \mathrm{~mm}$ \\
\hline Detection range & $100 \sim 1000 \mathrm{~mm}$ \\
\hline Output range & $0.24 \sim 2.40 \mathrm{~V}$ \\
\hline Workable temperature & $0 \sim 40^{\circ} \mathrm{C}$ \\
\hline
\end{tabular}

Table 3 Specification of NI DAQPad-6015 board.

\begin{tabular}{|c|c|}
\hline Analog inputs & 16 Channel \\
\hline Resolution & 6 bits \\
\hline Sampling rate & Max. $200 \mathrm{kS} / \mathrm{s}$ \\
\hline Input range & $\pm 10 \mathrm{~V}$ \\
\hline Triggering & Analog and digital \\
\hline
\end{tabular}

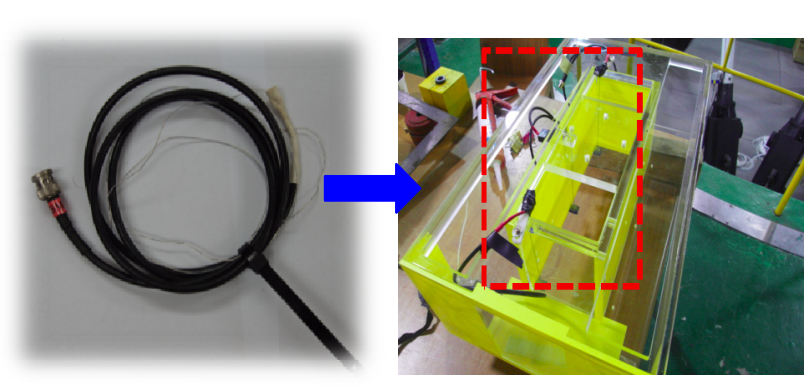

Fig. 3 Wave gauge and installation for measurement.

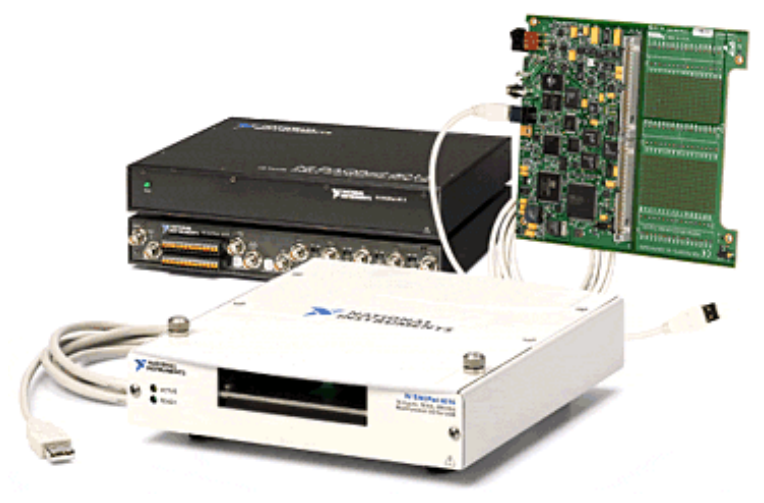

Fig. 4 NI data acquisition equipment.

\section{MODELS}

Three models are tested. One is 2D model which has 2D section of vessel in the vicinity of midship section including moonpool. Another is 3D model which has closed moonpool boundary. The other is 3D model with cofferdam. Last one is a typical moonpool shape that modern compact drillship has. Main dimensions of each model are shown in Table 4. 


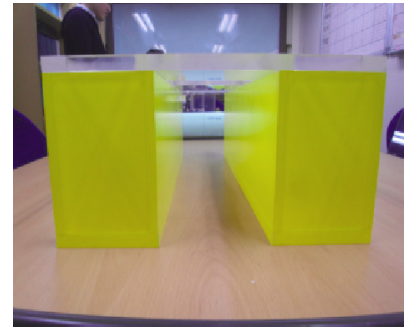

Model A.

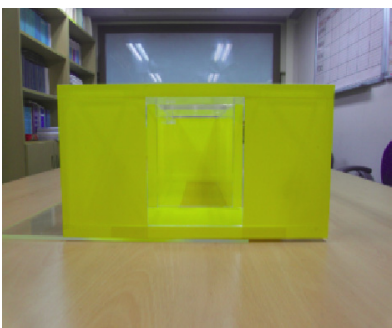

Model B.

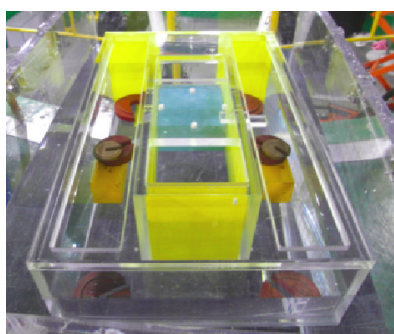

Model Bc.

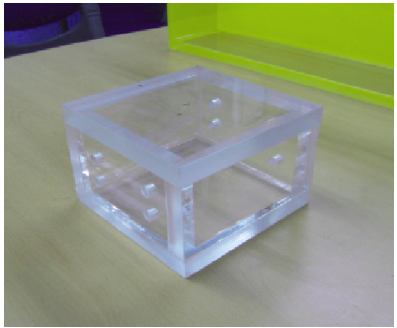

Cofferdam.

Fig. 5 Test models : Model A, Model B, Model Bc, and cofferdam.

Table 4 Main dimensions of each model.

\begin{tabular}{|c|c|c|c|}
\hline & \multicolumn{3}{|c|}{ Model A } \\
\hline L & 0.59 & 1 & 0.59 \\
\hline B & 0.36 & $\mathrm{~b}$ & 0.13 \\
\hline D & 0.18 & $\mathrm{~d}$ & 0.11 \\
\hline & \multicolumn{3}{|c|}{ Model B } \\
\hline L & 0.59 & 1 & 0.35 \\
\hline B & 0.36 & $\mathrm{~b}$ & 0.13 \\
\hline D & 0.18 & $\mathrm{~d}$ & 0.11 \\
\hline & & Model Bc & 0.35 \\
\hline L & 0.59 & $\mathrm{lc} *$ & 0.13 \\
\hline B & 0.36 & $\mathrm{bc} *$ & 0.11 \\
\hline D & 0.18 & $\mathrm{hc}$ & \\
\hline
\end{tabular}

$* \mathrm{lc}=$ cofferdam length, $\mathrm{bc}=$ cofferdam breadth, hc $=$ cofferdam height.

Model Bc has the same moonpool dimension but box type cofferdam inside moonpool is combined. One vessel model, four wave probes are installed in 2D wave flume.

The locations of wave probes are as follows: Wave Gauge 1 (WG1) and WG3 are located near wall of moonpool. WG2 is located in the center of moonpool. Location of wave probes of Model A are illustrated in Fig. 6.

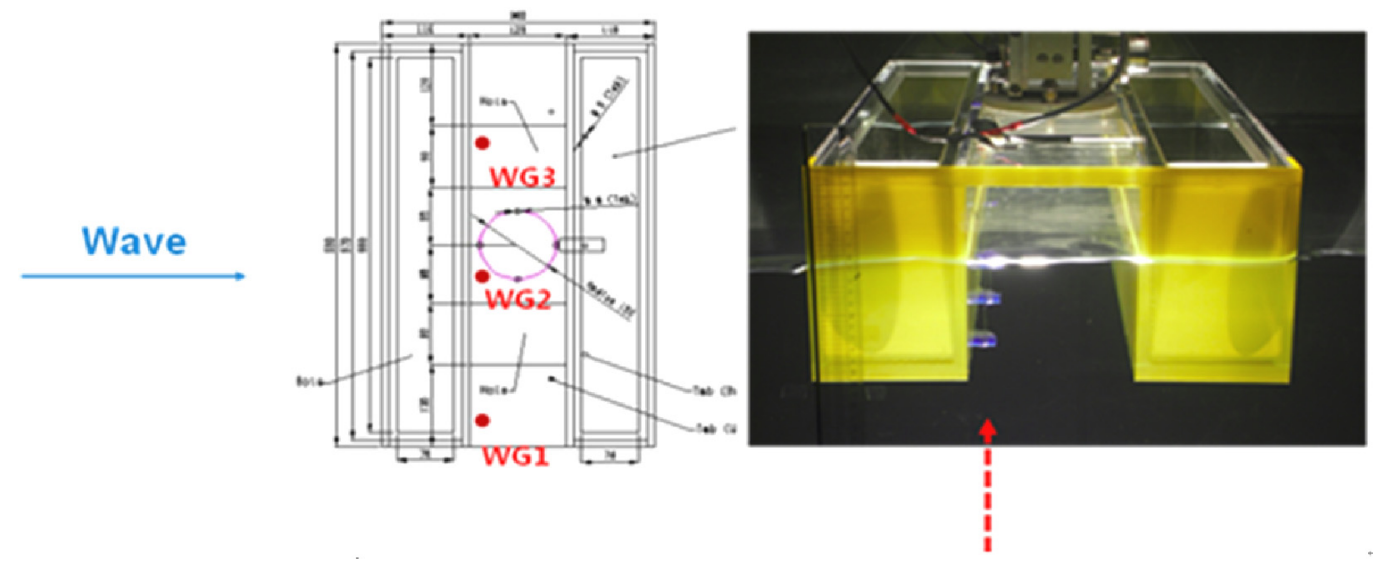

Fig. 6 Location of wave gauges of Model A-top view (left), front view (right). 


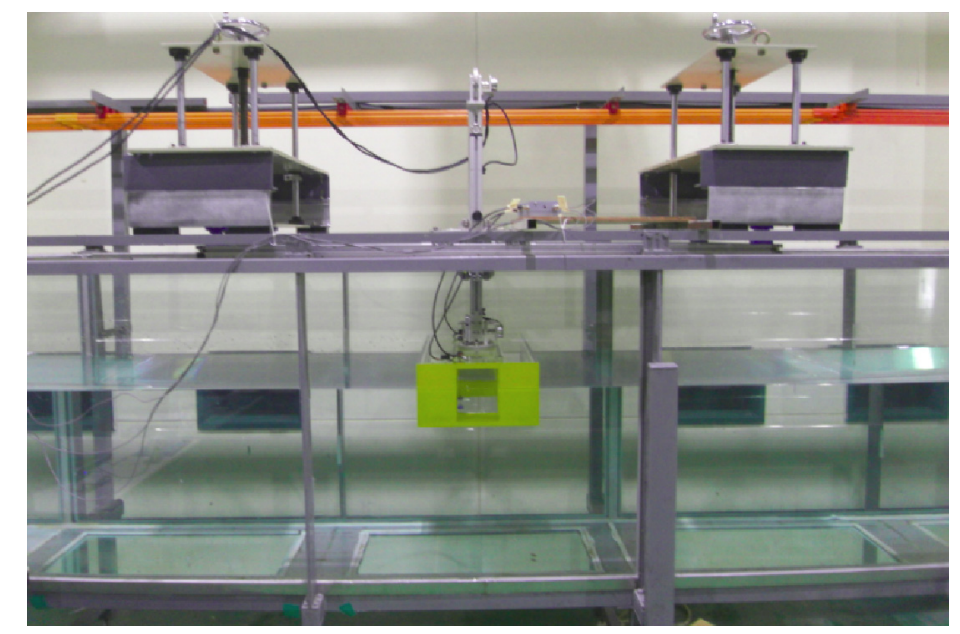

Fig. 7 Moonpool model installed for model test in 2D wave flume.

\section{EXPERIMENTS}

Model test considers fixed condition and motion free condition of the model. Relative water elevation inside moonpool and motion of the vessel are measured based on wave condition. To avoid the effect of coupling with roll motion, heave motion is only released in model test.

\section{WAVE CONDITION AND TEST CONDITION}

Wave conditions for model test are summarized in Table 5. Additional wave frequencies are selected around resonance frequency. Test conditions are summarized in Table 6. For each model, fixed condition and motion free condition are considered.

Table 5 Wave conditions for model test.

\begin{tabular}{|c|c|c|c|}
\hline Wave height $(\mathrm{cm})$ & Wave freq. $(\mathrm{Hz})$ & Wave period $(\mathrm{sec})$ & Remark \\
\hline 2.0 & 0.30 & 3.33 & \\
\hline 2.0 & 0.40 & 2.50 & \\
\hline 2.0 & 0.50 & 2.00 & \\
\hline 2.0 & 0.60 & 1.67 & \\
\hline 2.0 & 0.70 & 1.43 & \\
\hline 2.0 & 0.80 & 1.25 & \\
\hline 2.0 & 0.90 & 1.11 & \\
\hline 2.0 & 1.00 & 1.00 & \\
\hline 2.0 & 1.05 & 0.95 & Model A resonance (Molin's formula) \\
\hline 2.0 & 1.10 & 0.91 & Model B resonance (Molin's formula) \\
\hline 2.0 & 1.20 & 0.83 & \\
\hline 2.0 & 1.30 & 0.77 & \\
\hline 2.0 & 1.40 & 0.71 & \\
\hline
\end{tabular}


Table 6 Test conditions for model test.

\begin{tabular}{|c|c|c|c|}
\hline Model name & Test condition & D.O.F & \multirow{2}{*}{ Remark } \\
\hline \multirow{2}{*}{ Model A } & Motion free & Heave & \multicolumn{2}{|c}{ 3D model } \\
\cline { 2 - 3 } & Fixed & Heave & 3D model \\
\cline { 2 - 3 } Model B & Motion free & - & 3 \\
\cline { 2 - 3 } (with cofferdam)
\end{tabular}

\section{EXPERIMENTAL RESULTS AND ANALYSIS}

\section{Molin's formula}

Molin (2001) expressed moonpool resonance frequency of piston mode and sloshing mode as follows respectively:

Piston mode

$$
\omega_{n}=\sqrt{\frac{g}{h(1+C)}}
$$

where $g=$ acceleration of gravity, $h=\mathrm{draft}$,

$$
C=\frac{1}{2 \pi} \frac{1}{b l h}\left\{b^{2} l \arg \sinh \frac{l}{b}+b l^{2} \arg \sinh \frac{b}{l}+\frac{1}{3}\left(b^{3}+l^{3}\right)-\frac{1}{3}\left(b^{2}+l^{2}\right)^{\frac{2}{3}}\right\}
$$

Sloshing mode

$$
\omega_{n 0} \cong \sqrt{g \lambda_{n} \cdot \frac{1+J_{n 0} \tanh \left(\lambda_{n} h\right)}{J_{n 0}+\tanh \left(\lambda_{n} h\right)}}
$$

where, $g=$ acceleration of gravity, $\lambda_{n}=\frac{n \pi}{l}$,

$$
J_{n 0}=\frac{2}{n \pi^{2} r}\left\{\int_{0}^{1} \frac{r^{2}}{u^{2} \sqrt{u^{2}+r^{2}}}\left(1+(u-1) \cos (n \pi u)-\frac{\sin (n \pi u)}{n \pi}\right) d u+\frac{1}{\sin \theta_{0}}-1\right\}
$$

where, $\quad r=\frac{b}{l}, \tan \theta_{0}=r^{-1}$.

\section{Wave Gauge Relative Water Elevation (WG RWE) and Motion RAO}

The average values of time histories of incident wave and relative water elevation in moonpool were used. Regarding incident wave, measured data without the vessel were used because incident wave is reflected and diffracted by the model in $2 \mathrm{D}$ wave flume. And, steady state results of measured data for relative wave elevation and vessel motion were used.

WG RWE and Motion RAO are defined as follows. Piston mode moonpool resonance frequency are summarized in Table 7.

\begin{tabular}{|c|l|}
\hline WG RWE & Relative water elevation in moonpool / Incident wave \\
\hline Motion RAO & Vessel heave motion / Incident wave \\
\hline
\end{tabular}

*Relative water elevation in moonpool : distance from baseline of the model to free surface. 
Table 7 Summary of piston mode moonpool resonance frequencies.

\begin{tabular}{|c|c|c|c|}
\hline \multirow{2}{*}{ Model } & Test condition & Model test & Molin's formula \\
\hline \multirow{2}{*}{ Model A } & Motion free & 1.20 & 1.05 \\
\cline { 2 - 4 } & Fixed & 1.10 & - \\
\hline \multirow{2}{*}{ Model B } & Motion free & 1.20 & 1.10 \\
\cline { 2 - 4 } & Fixed & 1.12 & - \\
\hline \multirow{2}{*}{ Model Bc } & Motion free & 1.30 & - \\
\cline { 2 - 4 }
\end{tabular}

*Unit: $H z$

\section{Model A : motion free}

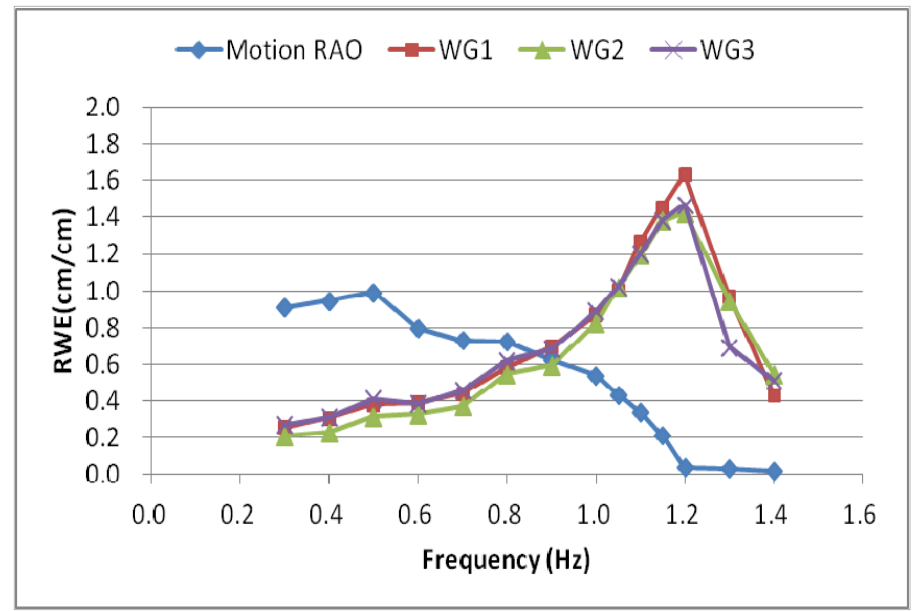

Fig. 8 RWE and motion RAO of Model A.

Moonpool resonance of Model A presents 1.20 Hz. Wave gauge1, wave gauge2, and wave gauge3 show same amplitude and same resonance frequency. Wave gauge 2 shows very little smaller amplitude when it is compared with wage gauge1 and wave gauge 3 due to wall effect.

\section{Model A : motion free vs. motion fixed}

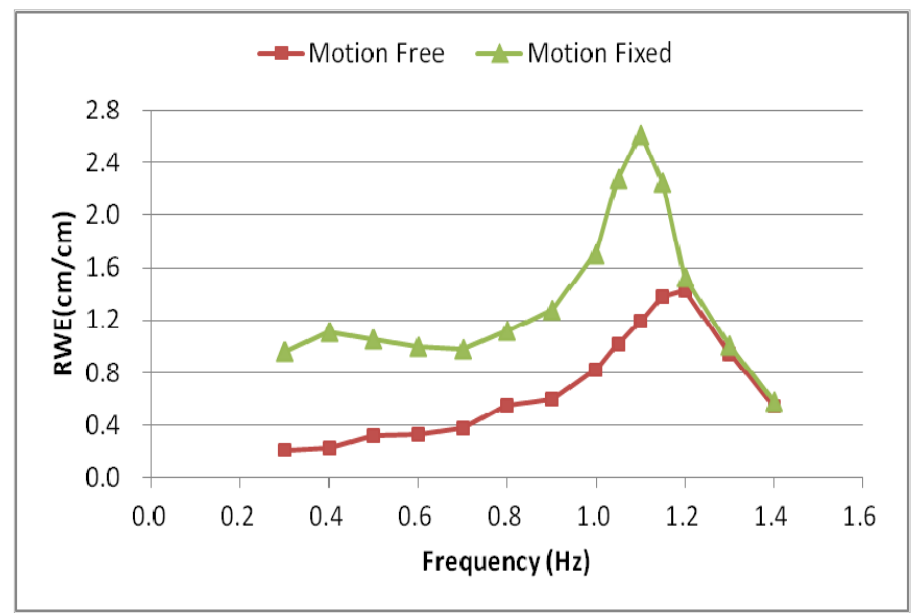

Fig. 9 Comparison of RWE between motion free condition and fixed condition of Model A. 
Moonpool resonances on motion free condition and fixed condition are $1.20 \mathrm{~Hz}$ and $1.10 \mathrm{~Hz}$ for each condition. Motion free condition presents $0.1 \mathrm{~Hz}$ higher resonance frequency than that of fixed condition. It is confirmed that Molin's formula predicted piston mode freuqency very accurately for fixed condition. However, resonance frequency for motion free condition shows shifted resonance frequency results.

Model B : motion free

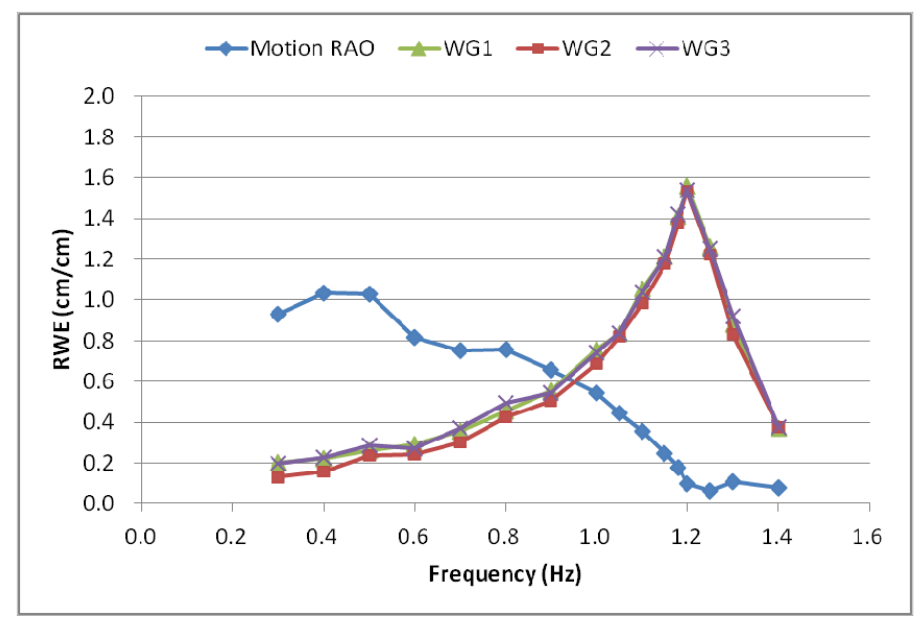

Fig. 10 RWE and motion RAO of Model B.

Moonpool resonance of Model B presents 1.20 Hz. Results of Model B are very similar that of Model A for motion free condition. Wave gauge1, wave gauge2, and wave gauge 3 show almost the same amplitude and resonance frequency.

Model B : motion free vs. motion fixed

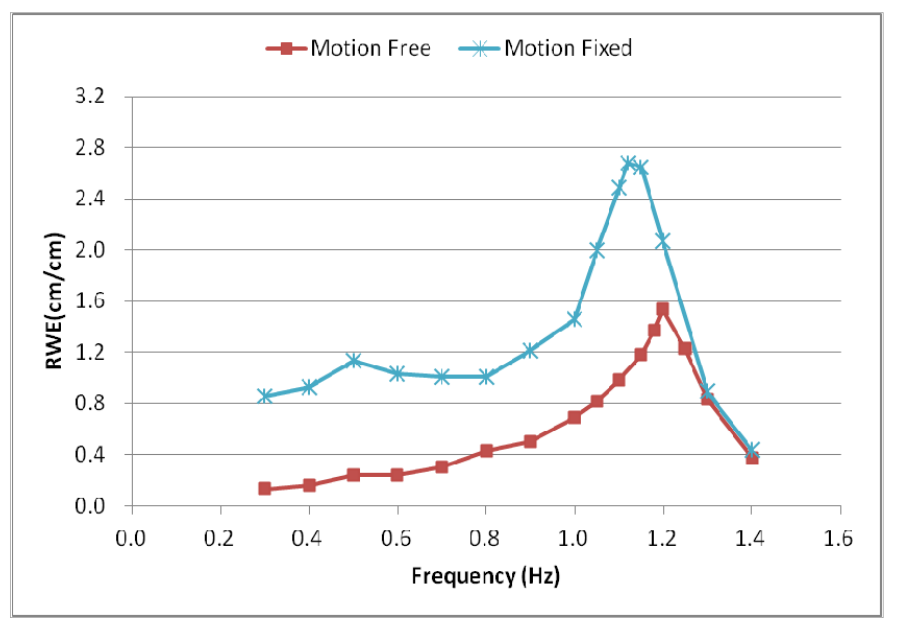

Fig. 11 Comparison of RWE between motion free condition and fixed condition of Model B.

Moonpool resonance frequency on motion free condition and fixed condition are $1.20 \mathrm{~Hz}$ and $1.12 \mathrm{~Hz}$ for each condition. Difference of resonance frequencies between Model A and Model B on fixed condition is $0.02 \mathrm{~Hz}$. This test results show very good agreement compared with $0.05 \mathrm{~Hz}$ difference of the predicted resonance frequencies from Molin's formula even though model test includes experimental error.

\section{Model Bc : motion free}

Resonance frequency of Model Bc presents $1.30 \mathrm{~Hz}$. Relative water elevation between wave gauge 2 and wave gauge 3 show 
some difference around resonance frequency. Resonance frequencies are located in two regions. One is high frequency region $(1.30 \mathrm{~Hz})$ and the other is low frequency region $(0.60 \mathrm{~Hz})$.

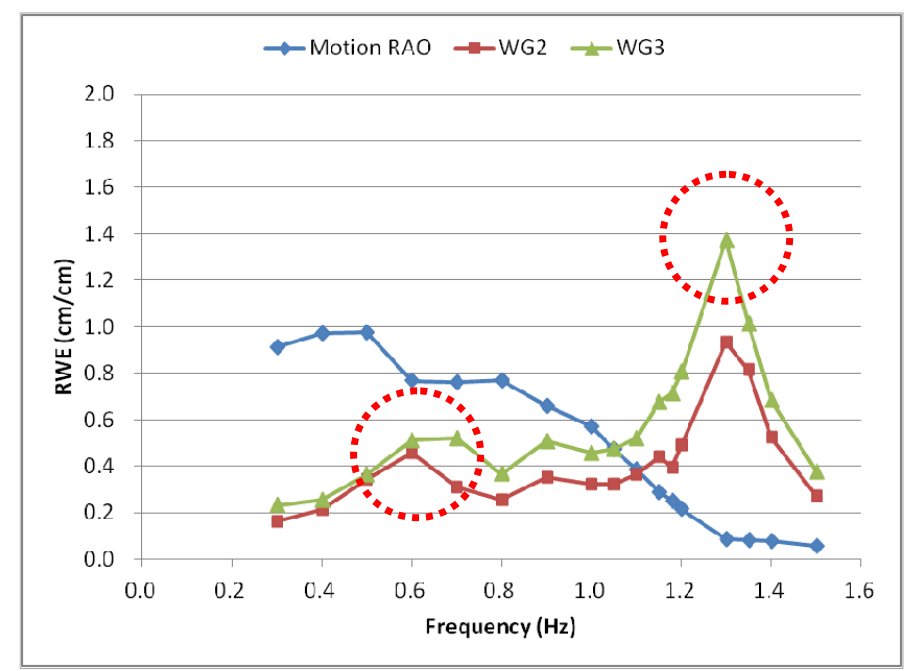

Fig. 12 RWE and motion RAO of Model Bc.

Model Bc : motion free vs. motion fixed

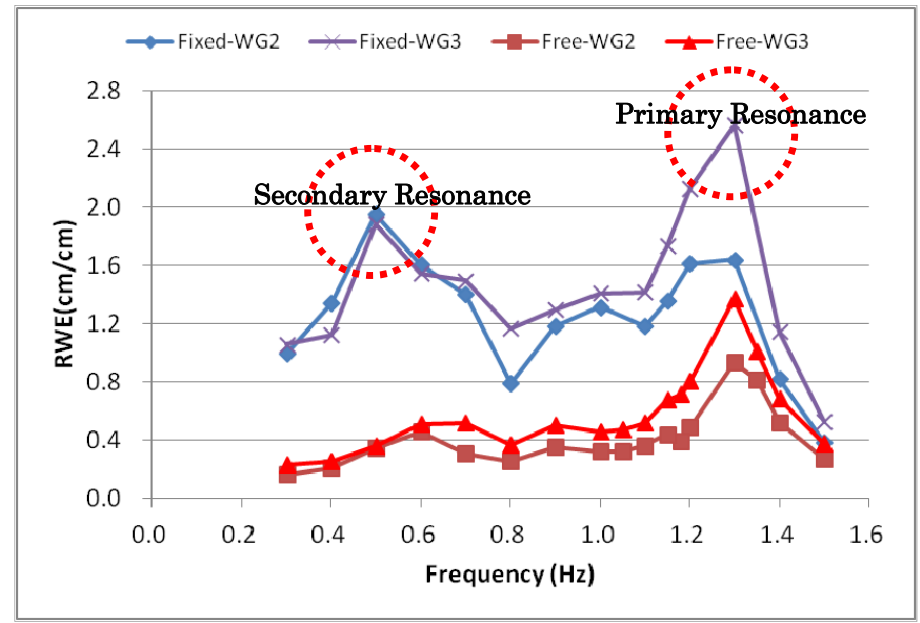

Fig. 13 Comparison of RWE between motion free condition and fixed condition of Model Bc.

In case of Model Bc, resonance frequencies on motion free condition and fixed condition present $1.30 \mathrm{~Hz}$. There is no difference of resonance frequency between two tests. Although resonance frequencies are located in high frequency region, secondary resonance was found in low frequeny region. In particular, secondary resonance is very clear for fixed condition compared with motion free condition.

\section{Cofferdam effect and longitudinal sloshing wave}

Fig. 14 shows comparison results between without cofferdam and with cofferdam. The model case with cofferdam inside moonpool indicates the shifted resonance frequency compared with the model without cofferdam. And also, cofferdam reduces relative water elevation $11 \%$ near wall and $39.6 \%$ in the center of moonpool. This means the cofferdam inside moonpool make resonance frequency shifted. In other words, it can be used the cofferdam as the effective design parameter at the initial design stage of offshore vessel. Keeping moonpool resonance frequency away from wave frequency of its design sea state can avoid violent flow in moonpool. Ultimately, operating performance of the vessel can be improved using this design strategy. 


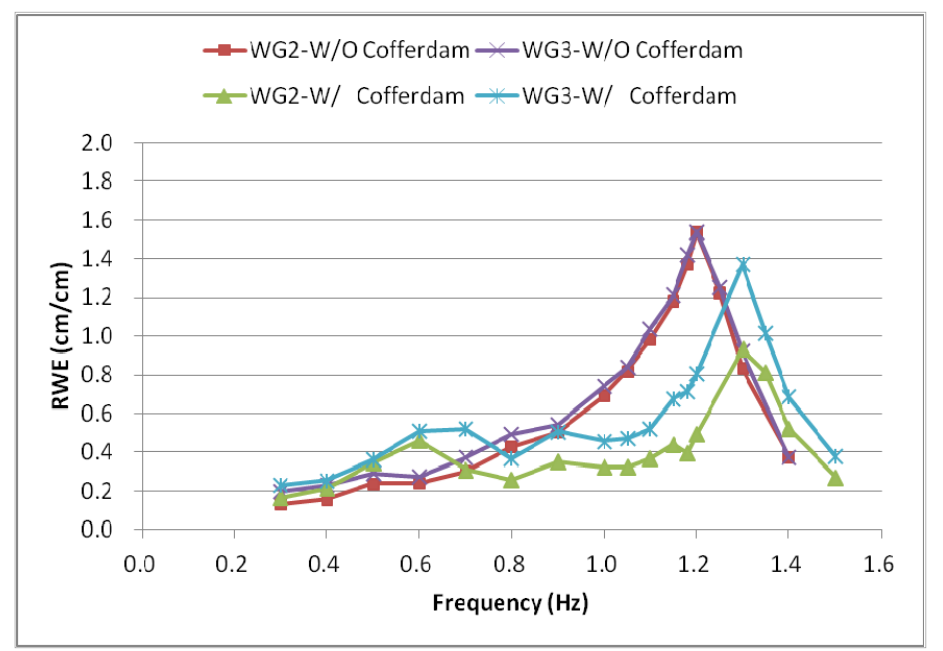

Fig. 14 Comparison of RWE between Model B (without cofferdam) and Model Bc (with cofferdam) for motion free condition.
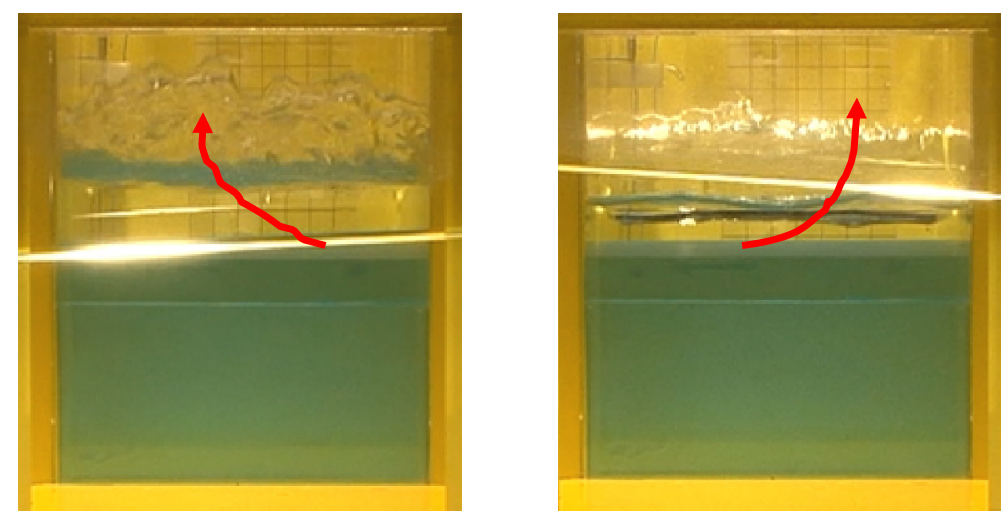

Fig. 15 Front moonpool wall (left) and rear moonpool wall (right).

Wave was generated in the longitudinal direction when the vessel was in beam sea. And, the overturn of free surface near at the end of cofferdam was observed through model test. Fig. 15 shows sloshing waves in longitudinal direction. Left photo shows front moonpool wall and right photo shows rear moonpool wall to longitudinal direction of vessel.

\section{CONCLUSIONS}

Model tests have been performed. Three models are tested and the followings are drawn based on the model test results.

(1) Molin's formula predicts piston mode frequency quite accurately.

(2) Motion free condition has higher resonance frequency when it is compared with that of motion fixed.

(3) The installation of cofferdams moves resonance frequency to higher region. It also generates secondary resonance at lower frequency.

(4) Cofferdams reduce the water elevation inside of the moonpool.

(5) Cofferdams were the cause of generating waves in the longitudinal direction when the ship was in beam sea.

\section{ACKNOWLEDGEMENT}

This work was supported by the National Research Foundation of Korea (NRF) grant funded by the Korea government (MEST) (No. 2011-0030670). 


\section{REFERENCES}

Choi, S.Y., Lee, Y.G. and Jung, K.Y., 2010. A fundamental study for internal flow in moonpool using marker-density method by two-dimensional numerical simulation. Spring Conference of the Society of Naval Architects of Korea. Je-Ju, Korea 3-4 June 2010.

Fukuda, K., 1977. Behavior of water in vertical well with bottom opening of ship and its effects on ship-motion. Journal of the Society of Naval Architects of Japan, 1977(141), pp.107-122.

Maisondieu, C. and Ferrant, P., 2003. Evaluation of the 3D flow dynamics in a moonpool. Proceedings of the Thirteenth International Offshore and Polar Engineering Conference. Honolulu, Hawaii, USA 25-30 May 2003.

Molin, B., 2001. On the piston and sloshing modes in moonpools. Journal of Fluid Mechanics, 430, pp.27-50.

Park, S.J., 2009. Hydrodynamic characteristics of moonpool shapes. MSc Thesis. Pusan National University.

Taylor, R.E., Sung, L. and Taylor, P.H., 2009. Gap resonances in focused wave groups. Proceedings of the $23^{\text {rd }}$ International Workshop on Water Waves and Floating Body. Je-Ju, Korea 13-16 April 2008.

Veer, R. and Tholen, H.J., 2008. Added resistance of moonpools in calm water. Proceedings of the ASME 27th International Conference on Offshore Mechanics and Arctic Engineering. Estoril, Portugal 15-20 June 2008.

Yang, S.H., Kwon, S.H., Park, J.B., Kim, M.S. and Lee, C.H., 2012. Research on the moonpool resonance effect to the motion of a modern compact drillship. Proceedings of the Annual Autumn Meeting of the Society of Naval Architects of Korea. Chang-Won, Korea 15-16 November 2012. 